\title{
ALOPECIA E CARACTERÍSTICAS FENOTÍPICAS DE FEMINIZAÇÃO ASSOCIADO A TUMOR DE CÉLULAS DE LEYDIG EM UM CÃO
}

\author{
Alopecia and Phenotipical Characteristics of Feminization \\ Associated with a Leydig Cell Tumor in a Dog
}

\author{
Carlos Maia Bettini ${ }^{1}$ \\ Rubiana Midori Anami \\ Maisa Martins Quirilos Assis ${ }^{2}$ \\ Eduardo Raposos Monteiro ${ }^{3}$ \\ Selwyn Arlington Headley ${ }^{4}$
}

\section{Resumo}

Descreveu-se a ocorrência de Tumor das células de Leydig associada à síndrome de feminização em um cão. O diagnóstico baseou-se nas manifestações clínicas (feminização, alopecia e ginecomastia) e as características histológicas consistentes de tumor de células intersticiais (Leydig).

Palavras-chave: Cão; Tumor; Células de Leydig.

\section{Abstract}

A Leydig tumor associated with the feminization syndrome is described in a dog. Diagnosis was based on clinical manifestations (feminization, alopecia, and gynecomastia) associated with the histological characteristics that were consistent with a Leydig tumor.

Keywords: Dog; Tumor; Leydig cells.

1 Médico Veterinário, Mestre, Doutor, Departamento de Radiologia e Clínica de Pequenos Animais, Hospital Veterinário, Centro Universitário de Maringá (CESUMAR), Av. Guedner 1610, Jd. Aclimação, Maringá, PR, Brasil. 87050-390 Fone/Fax: + (44) 3027 6360. E-mail: bettini@cesumar.br Autor para correspondência

2 Acadêmicas do Curso de Medicina Veterinária ,CESUMAR, Maringá, Paraná, Brasil.

3 Médico Veterinário, Mestre, Departamento de Anestesiologia, CESUMAR, Maringá, Paraná, Brasil.

4 Médico Veterinário, Mestre, Doutor, Laboratório de Patologia Veterinária, Departamento de Medicina Veterinária Preventiva, Universidade Estadual de Londrina. Londrina, Paraná, Brasil. 


\section{Introdução}

Os tumores testiculares são mais freqüentemente descritos em cães (PETERS et al., 2003). Entretanto, esses podem ser encontrados em outras espécies de animais domésticos (SANTOS et al., 2000). Esses tumores podem ser classificados em: 1) tumores de células germinativas, que incluem os seminomas, carcinoma embrionário e teratoma; 2) tumores do cordão estromal sexual, que incluem tumores das células de Sertoli e tumores das Células de Leydig; 3) tumores primários múltiplos; 4) mesotelioma; e 5) tumores vasculares e estroma (KENNEDY et al., 1998).

De acordo com Peters et al. (2003), os tumores testiculares mais freqüentemente descritos em cães são os das Células de Sertoli, seminomas e tumores das Células de Leydig, podendo ocorrer associados, uni ou bilateralmente.

Carcinoma embrionário e teratomas predominam em crianças e seminomas em adultos, mas tumores das células de Sertoli e das células intersticiais ocorrem em proporção equivalente ao seminoma no cão, mas são raros no homem (HAYES et al., 1990).

A feminização do macho é causada pelo hiperestrogenismo, sendo mais relacionada aos tumores das células de Sertoli, principalmente, aqueles encontrados em testículos cripotorquídicos (SCOTT et al., 1996). Entretanto, esta síndrome já foi descrita nos tumores das células de Leydig e seminomas (PETERS et al., 2003).

A síndrome de alopecia endócrina e feminização ocorrem em um terço dos cães com tumores testiculares das células de Sertoli, podendo ocorrer também, embora seja raramente e de maneira idêntica, em tumores de células intersticiais e seminomas (SCOTT et al., 1996). Essa síndrome é caracterizada por várias combinações de alopecia bilateral simétrica, ginecomastia, prepúcio pedunculoso, atração por outros machos da espécie e alopecia e/ou feminização (LIPOWITZ et al., 1973; SCOTT et al., 1996).

A maioria dos tumores das células intersticiais é benigno, embora formas malignas (carci- noma das células intersticiais) tenham sido descritas (MACLACHLAN; KENNEDY, 2002). Dentro do carcinoma da célula intersticial, as células são mais freqüentemente encontradas de forma irregular, as figuras mitóticas são mais numerosas e invasão vascular mais evidente. Todavia, a diferenciação entre tumor benigno ou maligno é feita simplesmente por meio da histopatologia na ausência de metástases (MACLACHLAN; KENNEDY, 2002).

Hayes et al. (1990), ao estudarem a demasia de seminomas observados em cães trabalhando no Vietnã, no serviço militar dos Estados Unidos, apresentavam significativamente um elevado risco de seminoma testicular e, independentemente, disfunção testicular. Experimentos mostraram disfunção testicular e alterações na espermatogênese em animais de laboratório expostos a herbicidas de fenol, ou tetraciclina, um antibiótico utilizado freqüentemente nesses cães (HAYES et al., 1990). Assim, o uso excessivo de tetraciclina pode ter contribuído para o aumento do risco de problemas testiculares observados nos cães trabalhando no Vietnã (HAYES et al., 1990).

Este artigo descreve a ocorrência de feminização do macho associado a um tumor das células intersticiais em um cão e serve para alertar os clínicos que outros tumores, além do sertolioma, podem induzir este comportamento.

\section{Relato de caso}

Um cão, sem raça definida, macho, seis anos de idade, com áreas multifocais de alopecia não pruriginosa e hiperpigmentação na região cervical, ventral do abdômen, tórax e parte posterior da coxa foi atendido no Hospital Veterinário, Centro Universitário de Maringá (CESUMAR), PR (FIGURA 1). Na avaliação do sistema reprodutivo, observou-se um aumento acentuado de volume do testículo esquerdo, ginecomastia e prepúcio pendular. $\mathrm{O}$ animal foi submetido à orquiectomia, os testículos foram fixados em solução de formalina a 10\% e enviados para avaliação histopatológica de rotina. 
FIGURA 1 - Cão, macho, decúbito dorsal, animal sendo submetido à orquiectomia. Aumento do testículo esquerdo e áreas multifocais de alopecia e hiperpigmentação na região ventral do abdômen, tórax e parte posterior da coxa.

Figure 1 - Dog, male, dorsal decubitus, animal being submitted to the orchiectomy. Increase of the left testicule and multifocal areas of alopecia and byper pigmentation in the ventral region of the abdomen, thorax and posterior part of the thigh.

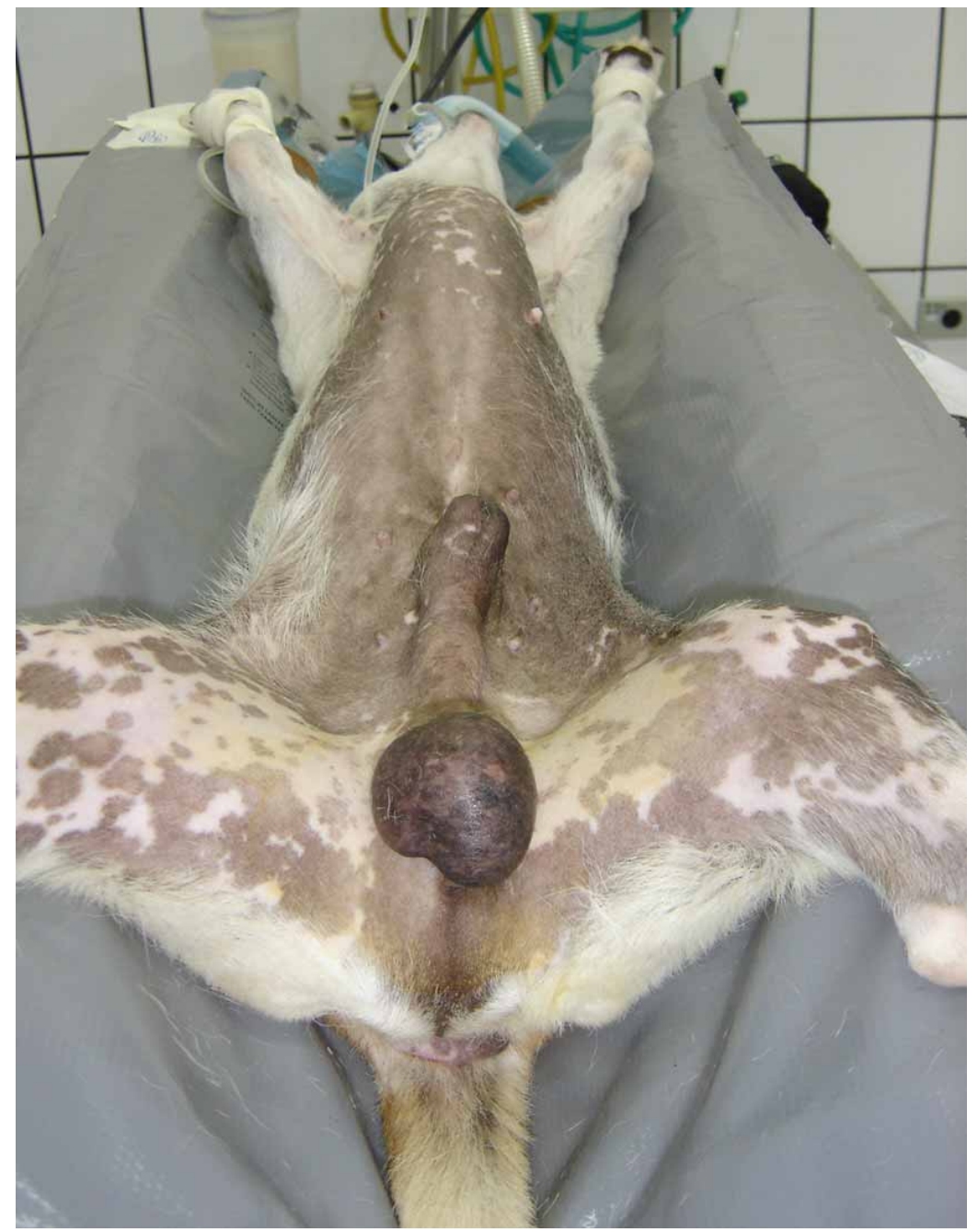

\section{Resultados e Discussão}

Macroscopicamente, o testículo direito apresentou-se atrofiado $(1,5 \times 3,5 \mathrm{~cm})$ e o esquerdo hipertrófico $(3,5 \times 7,0 \mathrm{~cm})$ (FIGURA 2). A superfície de corte do testículo di- reito apresentou-se firme e de aspecto normal, enquanto o testículo esquerdo mostrava a superfície de corte amolecida e com várias áreas avermelhadas medindo 0,5 a $1,5 \mathrm{~cm}$ de diâmetro e bem delimitadas por tecido esbranquiçado (FIGURA 3). 
FIGURA 2 - Cão, testículos. Direito atrofiado $(1,5 \times 3,5 \mathrm{~cm})$ e esquerdo hipertrófico $(3,5 \times 7,0 \mathrm{~cm})$. Figure 2 - Dog, testicules. Atrophied right $(1.5 \times 3.5 \mathrm{~cm})$ and hypertrophical left $(3.5 \times 7.0 \mathrm{~cm})$.

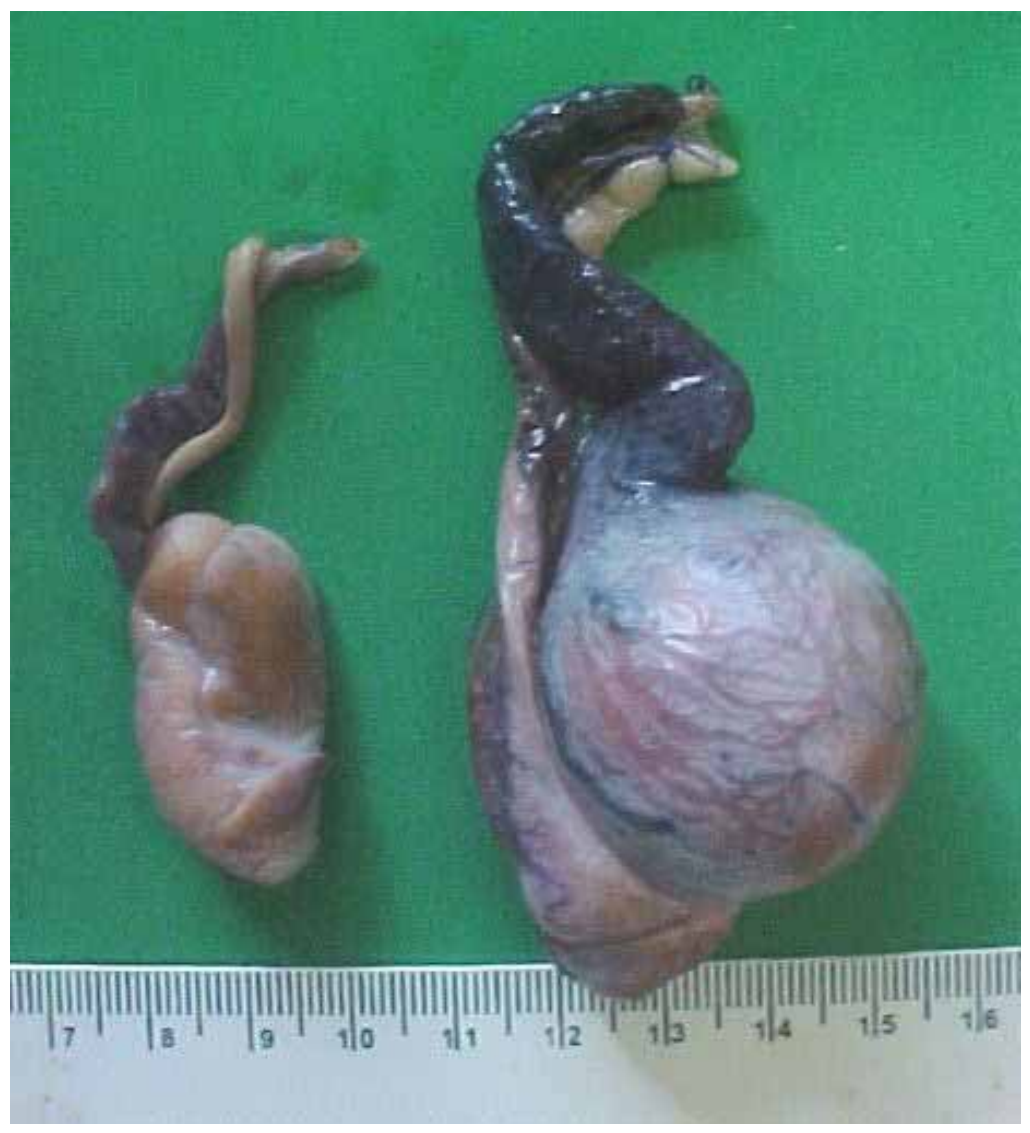

FIGURA 3 - Cão, testículos direito e esquerdo, corte transversal. Várias áreas avermelhadas e bem delimitadas por tecido esbranquiçado.

Figure 3 - Dog, right and left testicules, transversal cut. Some colored areas and well delimited by white tissue.

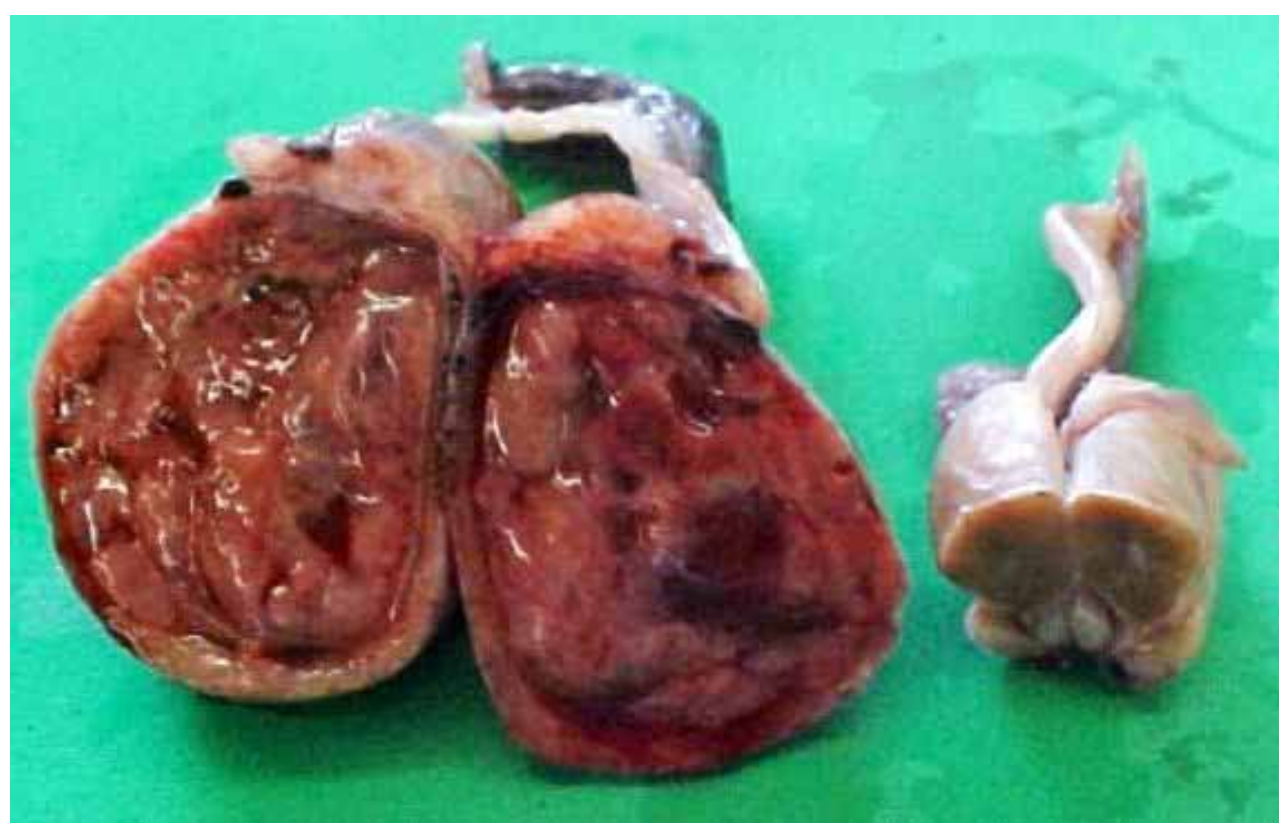


A avaliação histológica do testículo esquerdo revelou um tumor das células intersticiais, padrão angiomatóide, caracterizado pelos agrupamentos de células intersticiais (Leydig), resultando na formação de estruturas císticas ou vasculares, de tamanhos e formas diferentes, preenchidos por hemácias (FIGURA 4). As células neoplásicas se apresentavam de forma cúbica ou poliédrica, com citoplasma acidófilo e granular, algumas contendo gotículas de tecido adiposo. No testículo direito foi observado atrofia e deformação dos túbulos seminíferos (FIGURA 5).

FIGURA 4 - Fotomicrografia, testículo, cão. Tumor das células intersticiais de Leydig (HE. Obj. 4x). Figure 4 - Photomicrography, testicule, dog. Tumor of the Leydig interstitial cells (HE. Obj. $4 x$ ).

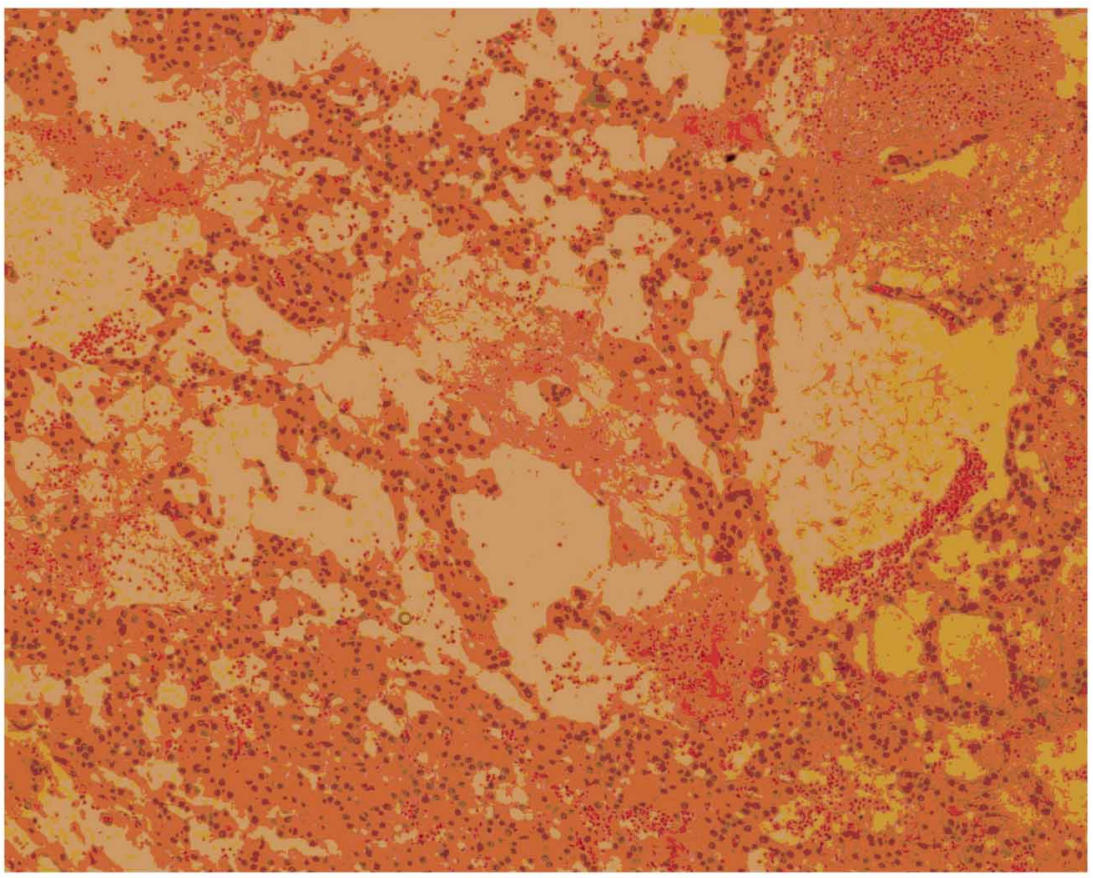

FIGURA 5-Fotomicrografia do Testículo, cão. Atrofia e deformação dos túbulos seminíferos (HE, 0bj. 10x). Figure 5 - Photomicrography of the Testicule, dog. Atrophy and deformation of the seminiferousducts (HE, Obj. 10x).

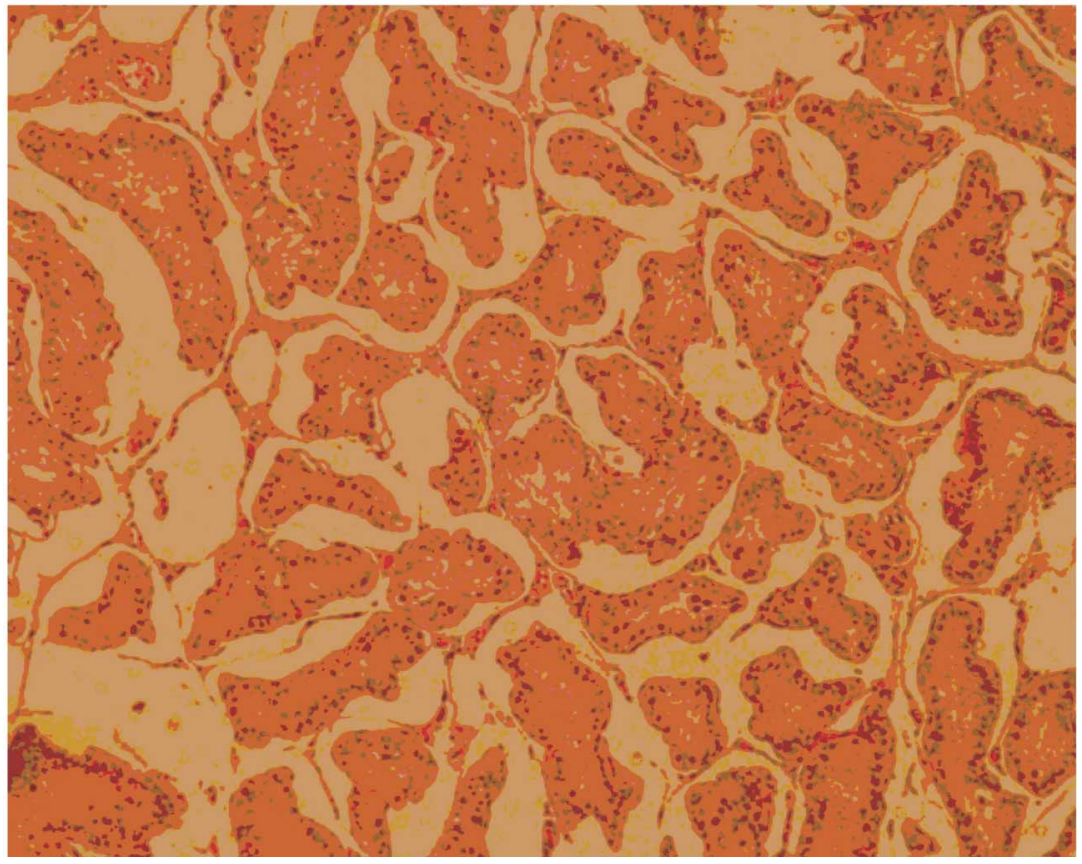


As alterações histológicas observadas no testículo esquerdo são consistentes com aquelas descritas na literatura sobre um tumor de células intersticiais (Leydig), tipo angiomatóide (NIELSEN; KENNEDY, 1990). O tumor pode ser classificado histologicamente em três padrões: 1) sólido-difuso, 2) cístico-vascular (angiomatóide), e 3) pseudoadenomatoso (NIELSEN; KENNEDY, 1990). Entretanto, não existe uma relação definida entre o comportamento biológico do tumor e os padrões histológicos (LADDS, 1993).

As manifestações de feminização, alopecia e ginecomastia observadas nesse caso já foram descritas em associação ao tumor intersticial de Leydig em cães (LIPOWITZ et al., 1973; SUESS et al., 1992). Entretanto, essas alterações são mais freqüentemente relacionadas ao sertolioma e seminoma (NIELSEN; KENNEDY, 1990). Em alguns casos do tumor das células intersticiais pode ocorrer uma marcada hipoplasia da medula óssea (SUESS et al., 1992).

As células intersticiais do animal normal secretam o hormônio masculino e são responsáveis pelas características sexuais secundárias do macho, porém, geralmente, as células tumorais não apresentam nenhum efeito hormonal no animal acometido (NIELSEN; KENNEDY, 1990). Todavia, alguns tumores das células intersticiais em cães demonstram uma produção aumentada de estrogênio (LADDS, 1993). Feminização em cães tem sido relacionada ao hiperestrogenismo absoluto ou relativo, mas o mecanismo exato é desconhecido (SUESS et al., 1992). As teorias dessa manifestação incluem síntese aumentada de estrogênio das células neoplásicas testiculares, metabolismo aumentado, transformação de compostos de androgênio por tecidos periféricos ou células neoplásicas, ou um desequilíbrio na quantidade de androgênioestrogênio (SUESS et al., 1992).

Embora células intersticiais normais secretem andrógenos, o tumor das células intersticiais não produz manifestação excessiva de secreção de andrógenos. Resumidamente, o aspecto do tumor das células intersticiais é bem característico, ou seja, é pequeno, apresenta uma deformidade aguda que afeta o testículo, com coloração amarelada a marrom, macio, bem circunscrito, e precisamente delineado pelo testículo adjacente. Eles tendem a salientar em superfícies cortadas e em algumas áreas que possuem hemorragias ou cistos (MACLACHLAN; KENNEDY, 2002).
O tumor das células intersticiais é bem descrito no cão, não freqüente no touro, e muito raro no gato, cavalo, suíno e caprino (NIELSEN; KENNEDY, 1990). Esse tumor é observado principalmente no testículo, mas já foi descrito no escroto, abdômen e na região inguinal (LIPOWITZ et al., 1973). Adicionalmente, os tumores das células intersticiais em cães são mais freqüentemente descritos em cães com mais de oito anos de idade (LIPOWITZ et al., 1973; NIELSEN; KENNEDY, 1990). Esses são mais freqüentes no testículo direito que no esquerdo (LIPOWITZ et al., 1973). Neste caso, o tumor foi encontrado no testículo esquerdo, com o direito atrofiado.

O que está de acordo com o estudo realizado por Santos et al. (2000), que observaram a incidência de $9,45 \%$ de tumores testiculares em cães, em que 43,28\% correspondia a tumores das células de Leydig, 29,85\% de Seminomas e 26,86\% de Tumores das Células de Sertoli, e apenas três dos testículos avaliados eram criptorquidas.

Segundo estudos por Peters et al. (2000), a prevalência de tumores em cães aumenta proporcionalmente com a idade. Observou-se que 86\% dos tumores clinicamente identificados e $57 \%$ dos tumores sem sinais clínicos foram encontrados em cães geriatras (PETERS et al., 2000). Seminomas e tumor das células de Leydig são mais freqüentes que tumor das células de Sertoli. Com o aumento da idade do cão não há diminuição na espermatogênese, entretanto, a incidência de tumores testiculares aumenta com a idade e isso afetou significantemente a espermatogênese (PETERS et al., 2000).

As características fenotípicas de feminização como prepúcio pendular, ginecomastia, alopecia e hiperpigmentação observadas nesse animal são características da síndrome da feminização do macho associada aos tumores testiculares (SCOTT et al., 1996).

Peters et al. (2003), ao estudarem a expressão genética em animais normais e com tumores testiculares, observaram uma menor expressão da aromatase em seminomas e tumores mistos em testículos normais, quando comparadas à expressão em testículos com tumores das células de Sertoli e tumores das células de Leydig. Esses aspectos foram avaliados em animais com presença de feminização.

$\mathrm{Na}$ estereidogênese testicular, as células de Leydig por meio das enzimas citocromo P450scc 
de clivagem da cadeia lateral (P450scc) e 3 $\beta$-hidroxiesteróide desidrogenase ( $3 \beta-\mathrm{HSD}$ ) realizam a conversão do colesterol para pregnenolona e de pregnenolona para progesterona, respectivamente. Para que isso ocorra, o colesterol deve estar hidroxilado na membrana mitocondrial (SILVA JÚNIOR; FRANÇA, 2001). Algumas proteínas são apontadas como reguladoras da função estereidogênica, como a SCP (transporte), a SAP (ativação), StAR (regulação) e a SIP (indução), que em células de Leydig tumorais sua estimulação parece ser independente de segundo mensageiro, estimulando a fosforilação de resíduos de Tirosinoquinase, proteínas específicas, estimulando de modo geral a estereidogênese e proliferação de células de Leydig imaturas (SILVA JÚNIOR; FRANÇA, 2001).

A partir da pregnenolona podem seguir duas vias diferentes, a via $\Delta^{4}$ dos cetoesteróides e a $\Delta^{5}$ dos hidroxiesteróides (SILVA JÚNIOR; FRANÇA, 2001). O cão, por sua vez, utiliza pelo menos parte do caminho $\Delta^{5}$ (pregnenolona, $17 \alpha$-hidroxipregnenolona, deidroepiandrostenediona, androstenediona, testosterona) (SILVA JÚNIOR; FRANÇA, 2001).

Segundo Silva Júnior; França (2001), pela enzima citocromo P450 $17 \alpha$-hidroxilase $/ \mathrm{C}_{17-20}$-liase (P450c17) formam-se os esteróides C19 (diidroepiandrosterona e androstenediona). Os metabólitos resultantes dessas reações passam a ter funções fisiológicas específicas na regulação do sistema genital (PAYNE; O'SHAUGHNESSY, 1996).

A testosterona é o principal andrógeno secretado pelas células de Leydig (SILVA JÚNIOR; FRANÇA, 2001). O metabolismo dos andrógenos no sítio de produção e nos tecidos-alvo periféricos é determinante para sua ação e seu efeito biológiCO (SUNDARAM; KUMAR, 1996). No sítio de produção, além dos processos biossintéticos, outros mecanismos metabólicos, como redução, hidroxilação, aromatização e conjugação podem regular o acúmulo ou secreção da testosterona pelo testículo (SILVA JÚNIOR; FRANÇA, 2001).

$\mathrm{Na}$ aromatização, a testosterona e androstenediona são convertidas em estrógenos, os quais possivelmente regulam sua própria produção (SILVA JÚNIOR; FRANÇA, 2001). A expressão da aromatase em tumores das células de Leydig resulta no aumento do nível de estradiol periférico e venoso no testículo, possivelmente devido ao fato de a enzima aromatase não apresentar taxa limite para a formação de estrógeno, ao menos que esse comece a saturar, condição que é pouco provável, pois é baixo o nível de testosterona em cães com tumores de Sertoli (PETERS et al., 2000). Outra hipótese é que ocorra a redução da expressão da $5 \alpha$-redutase do tipo I, havendo, assim, mais substrato de testosterona disponível para a enzima aromatase converter estradiol, pois ambas enzimas usam andrógenos como substrato (PETERS et al., 2003). Segundo os mesmos autores, outra possibilidade é que o nível da enzima 17beta-HSD, que converte estradiol em estrona, diminua sua atividade e, conseqüentemente, acumule estradiol.

\section{Conclusões}

De acordo com as alterações clínicas associadas às características histopatológicas, podese concluir que as lesões caracterizaram um tumor intersticial de Leydig.

\section{Agradecimentos}

Ao laboratório de Patologia do Hospital Veterinário do Cesumar, junto com todo o seu quadro de funcionários.

\section{Referências}

HAYES, H. M. et al. Excess of Seminomas observed in Vietinam service U.S. military working dogs. Journal of the National Cancer Institute，v. 82, n. 12, p. 042-1046, 1990.

KENNEDY, P. C.; CULLEN, J. M.; EDWARDS, J. F. et al. Histological Classification of Tumors o the Genital System of Domestic Animals. Washington: Armed Forces Institute of Pathology, 1998.

LADDS, P. W. The male genital system. In: JUBB, K. V. F.; KENNEDY, P. C.; PALMER (Eds). Pathology of domestic animals, 1993. 3. ed., cap. 5, p. 471-528.

LIPOWITZ, A. L. et al. Testicular neoplasms and concomitant clinical changes in the dog. Journal of the American Veterinary Medical Association, v. 163, n. 12, p. 1364-1368, 1973.

MACLACHLAN, N. J.; KENNEDY, P. C. Tumors of the genital systems. In: MEUTEN, D. J.

Tumors in domestic animals. 4. ed. Iowa: Iowa State, 2002. Cap. 11, p. 547-573. 
NIELSEN, S. W.; KENNEDY, P. C. Tumors of the genitial systems. In: MOULTON, J. E.

Tumors in domestic animals. 3. ed. Los Angleses: University of California, 1990. Cap. 11, p. 479-517.

PAYNE, A. H.; O' SHAUGHNESSY, P. J. Structure, function and regulation of steroidogenic enzymes in the Leydig cell. In: PAYNE, A. H.; HARDY, M. P.; RUSSELL, L. D. (eds). The Leydig cell. Vienna; Cache River, 1996. Cap. 12, p. 259-286.

PETERS, M. A. J. et al. Ageing, testicular tumors and the pituitary-testis axis in dogs. J. Endocrinol, n. 166, p. 153-161, 2000.

PETERS, M. A. J.; MOL, J. A.; WOLFWREN, M. E. V. et al. Expression of the insulin-like Growth Factor (IGF) System and Steroidogenic Enzymes In canine Testis Tumor. Reprod. Biol. and Endocrinol., v. 1, n. 22, 2003.

PETERS, M. A. J.; ROOIJ, D. G.; TEERDS, K. J.; et al. Spermatogenesis and testicular tumours in ageing dogs. Journal of reproduction and fertility, p. 443-452, 2000.

SANTOS, R. L.; SILVA, C. M.; RIBEIRO, A. F. C. et al. Testicular Tumors in Dogs: Frequency and Age Distribuition. Arq. Bras. Med. Vet. Zootec. v. 52, n. 1, Belo Horizonte, 2000.
SCOTT, D. W. et al. Dermatologia de Pequenos Animais. 5. ed. Rio de Janeiro: Interlivros, p. 1130. 1996.

SILVA JÚNIOR, V. A.; FRANÇA, L. R. Células de leydig e esteroidogênese em mamíferos. In: NUNES, I. J. Cadernos técnicos de veterinária e zootecnia: Andrologia-primeira parte, n. 35, p. 196. Belo Horizonte: FEP MVZ, 2001.

SUESS, R. P. et al. Bone marrow hipoplasia in a feminized dog with an interstitial tumor. Journal of the American Veterinary Medical Association, v. 200, n. 9, p. 1346-1348, 1992.

SUNDARAM, K.; KUMAR, N. Metabolism of testosterone in the Leydig cell and peripheral tissues. In:_. PAYNE, A. H; HARDY, M. P.; RUSSELL, L. D. The Leydig cell. Vienna: Cache River, 1996. Cap. 13, p. 287-306.
Recebido: 08/12/2005

Aprovado: 31/03/2006 